\title{
Dynamic Control of Fuel Cell Powered Water Pumping Station
}

\author{
Adel M. Sharaf \\ and \\ Mohamed A. H. El-Sayed \\ Centre of Energy Studies \\ University of Trinidad and Tobago \\ Point Lisas Campus, Esperanza Road, Brechin Castle, Couva, Trinidad W.I. \\ Phone/Fax number:+1868 7997551, e-mail: mohamed.el-sayed@utt.edu.tt, adel.sharaf@utt.edu.tt
}

\begin{abstract}
An efficient renewable green energy system consisting a hydrogen PEM-fuel cell as an energy sources is simulated and studied in this paper. The proposed green scheme has four separate key components. The first is the green power generation source. The second is the interfacing DC-DC converter used to connect green power generator fuel cell to the load bus. The third is a common DC interface-bus where the generated energy is collected in a DC form. The fourth comprises all interfacing error driven controllers and novel modulated green plug power filter (GPPF) used to reduce ripple variations and stabilize the common DC-Bus voltage. In this paper, the novel multi-loop error driven dynamic controller scheme is implemented for speed control of the PMDC motor. This multi-loop controller comprises three basic loops, the main supplementary dynamic momentum loop to ensure fast dynamic and minimum current and torque ripple content.
\end{abstract}

The proposed fuel cell generation scheme provides efficient and optimum dynamic operation to enhance system performance and secure energy supply. The proposed integrated hybrid system with all subsystems has been simulated using the Matlab Simulink/Sim-Power software environment and validated for voltage stabilization, efficient utilizations and enhanced power quality under different operating conditions, sudden load excursions, despite the non-linear volt-ampere characteristic of the fuel cell DC generator source.

\section{Key words}

Multi-loop dynamic control, fuel cells, PMDC motor drive, DC-DC-chopper, green plug power filter

\section{Introduction}

Recently a growing interest on utilizing renewable and green energy has been motivated by rapidly increasing oil prices, limited fossil fuel reserves and growing environmental green awareness. Renewable and green energy sources such as hydrogen, solar, wind, tidal and wave are all considered as alternative, renewable and green energy generation for replacement for fossil fuel oil, natural gas and coal. Hydrogen or hydrocarbons itself is clean, sustainable and emission free fuel. Whereas the 19th Century was the century of the steam engine and the 20th Century was the century of the internal combustion engine, it is likely that the 21 st Century will be the century of the fuel cell. Full cells are now on the verge of being introduced commercially, revolutionizing the way we presently produce power. Fuel cells can use hydrogen as a fuel, offering the prospect of supplying the world with clean, sustainable electrical power.

A fuel cell by definition is an electrical battery cell, which unlike storage cells can be continuously fed with a fuel so that the electrical power output is sustained indefinitely. They convert hydrogen, or hydrogencontaining fuels, directly into electrical energy plus heat through the electrochemical reaction of hydrogen and oxygen into water. The process is that of electrolysis in reverse as shown in Figure (1). Because hydrogen and oxygen gases are electrochemically converted into water, fuel cells have many advantages over heat engines. These include: high efficiency, virtually silent operation and, if hydrogen is the fuel, there are no pollutant emissions. If the hydrogen is produced from renewable energy sources, then the electrical power produced can be truly sustainable. Currently hydrogen energy research is concentrating on the development of efficient and safe fuel cell technology. Enhancing the output efficiency and improving the performance of fuel cell are among main research topics $[1,2]$.

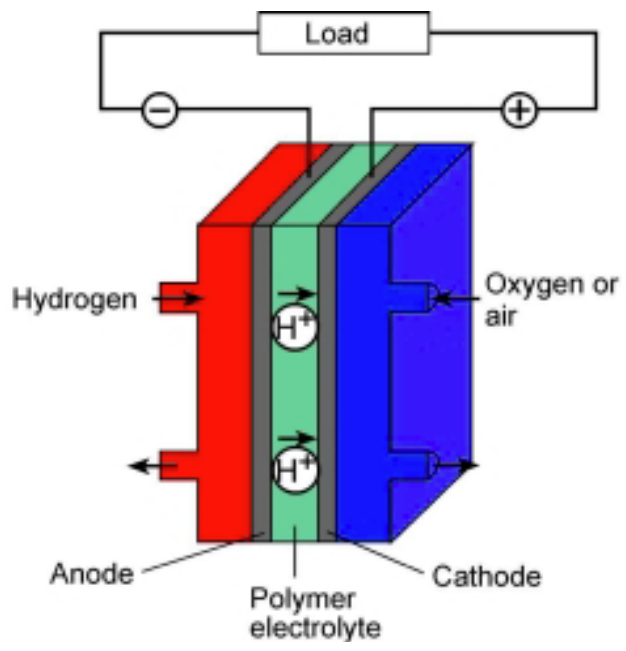

Figure (1). Diagram of a single fuel cell. 
When an electrical load is attached across the anode and cathode of the fuel cell, a working voltage is produce between 0.5 and 0.8 volts, depending on the cell operation conditions. To create practical working voltages, individual cells are stacked together in series to form a fuel cell stack. The actual open circuit voltage of the cell is less than the ideal voltage because of different loss mechanisms. The total voltage drop is the sum of activation polarization, resistive losses ( $i R$ drop) and concentration polarization drop.

The Electrochemical voltage behavior of the fuel cell is commonly modeled using the simple equivalent first order circuit shown in Figure (2). This circuit consist three passive circuit elements that result in a first order approximation of the dynamic response of the electrochemical capacitor. The circuit includes the double layer capacitance $\mathrm{C} 1, \mathrm{Rr} 1, \mathrm{Rm}, \mathrm{C} 2, \mathrm{Rr} 2$. The equivalent series resistance that represents the energy lost due to the distributive resistance of the electrolyte, electronic contacts and the porous separator $[3,4]$.

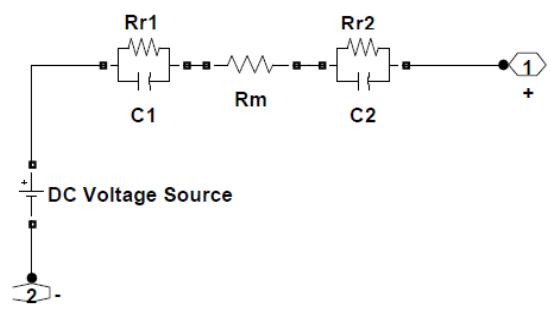

Figure (2) Electrical equivalent circuit of fuel cell

The industrial applications of fuel cell technology are still limited to hybrid electric vehicles. Little papers are dealing with the power system application of fuel cell and system interactions. Therefore, the interaction of fuel cell with power system components and switching electronic drives for motors, choppers and controllers are crucial. In this paper fuel cell stack supplying power to a common DC bus is considered for transferring electrical energy to a permanent magnet DC motor for village irrigation and water pumping applications.

\section{Study System}

The proposed system consists of four parts. The fuel cell stack in parallel with a DC battery, DC-DC-4 quadrant converter/chopper, The tri-loop nonlinear controller and PMDC motor driving the water pump. PMDC motors are usually preferable due to their reliability, durability, low cost, low voltage characteristics, positive conversion coefficient between electrical and mechanical parts, sizing and design flexibility. Figure (3) depicts the sample studied fuel cell motorized scheme.

A permanent magnet dc (PMDC) motor converts electrical energy provided by a voltage source to mechanical power provided by a spinning rotor by means of magnetic coupling. The parameters and symbols which were used in simulating the system are given in Appendix of the paper. The armature coil of the DC motor is represented by an inductance (Lm) in series with resistance $(\mathrm{Rm})$ in series with an induced voltage (Em) which opposes the voltage source. A differential equation for the equivalent circuit is derived by using Kirchhoff's voltage law around the electrical loop.

$$
\begin{aligned}
& \mathrm{E}=\mathrm{Ke} \omega \\
& \mathrm{V}-\mathrm{E}=\mathrm{RI}+\mathrm{L}[\mathrm{dI} / \mathrm{dt}]
\end{aligned}
$$

PMDC Motor Load Equations can be expressed by:

$$
\begin{aligned}
& \mathrm{TL}=\mathrm{K} \omega^{2} \\
& \mathrm{~T}_{\mathrm{M}}=\mathrm{K}_{\mathrm{T}} \mathrm{I} \\
& \mathrm{T}_{\mathrm{M}^{-}}-\mathrm{T}_{\mathrm{L}}=\mathrm{J}[\mathrm{d} \omega / \mathrm{dt}]+\mathrm{B} \omega
\end{aligned}
$$

Where $\omega$ is the motor angular velocity, $T_{M}$ is the motor torque, $\mathrm{T}_{\mathrm{L}}$ is the load torque, $\mathrm{K}_{\mathrm{T}}$ is the torque constant and $\mathrm{J}, \mathrm{B}$ are the motor inertia and friction coefficients.

\section{Control Strategy}

In this paper, the novel tri-loop error driven dynamic controller scheme shown in Figure (4) is implemented for speed control of the PMDC motor, which comprises three basic loops, namely the main speed stabilization loop, the motor current dynamic error loop, and the supplementary dynamic momentum tracking loop. The additional dynamic loops ensure energy efficient utilization and reduced current ripple content [5].

1. The speed variation from its reference values is the main loop for voltage stabilization. The control signal weight $\gamma_{\mathrm{s}}$ is selected as 1 .

2. The load current is the dynamic error coordinative type minimum load current excursion from maximum motor current. The weight $\gamma_{\mathrm{I}}$ is selected as 0.5 , to include the changes and excursions in load current.

3. The dynamic momentum loop with the weight $\gamma_{P}$ selected as 0.5 to minimum excursion of motor momentum.

The total error signal $\left(e_{t}\right)$ is the sum of these three basic dynamically scaled loop errors that presents by:

$$
\mathrm{e}_{\mathrm{t} 1}=\left(\gamma_{\mathrm{s}} \mathrm{e}_{\mathrm{s}}+\gamma_{\mathrm{i}} \mathrm{e}_{\mathrm{i}}+\gamma_{\mathrm{m}} \mathrm{e}_{\mathrm{m}}\right)
$$

The tri-loop compensate for any dynamic oscillations in bus voltage, motor current at the DC bus. The loop weighing factors are assigned to ensure loop time scaling and dominant loop (1) control action. The total error signal to ensure maximum power utilization of the triloop is driven through a PI controller that is used to compensate the dynamic total error in order to provide control signal $\beta$, which is then converted to degrees as phase angles. This phase angles are then sent to the Pulse Width Modulated (PWM) generator through saturation to adjust the sequence of the two IGBT/Diode switch 
triggering which is shown in Figure 4. The control gains (Kp, and $\mathrm{Ki}$ ) are selected to minimize an objective function, which is used for flickers migration, the voltage stabilization enhancement, and efficient energy utilization [6]. The novel tri-loop dynamic controller is validated for voltage stabilization and dynamic reactive compensation using Matlab/ Simulink/SimPower Toolbox software environment.

The proposed dynamic control strategy is essentially based on constructing a robust adaptive PMDC motor derive under the assumption that all motor parameters along with the load torque are time-varying, nonlinear and uncertain. The adaptive control scheme is able to guarantee the tracking of a time-varying trajectory with minimum steady state error. Without any information on the applied load torque; it is also required that the new adaptive control scheme is insensitive to any drive system nonlinearity, parametric change and sudden torque excursions.

\section{Green Plug Power Filter GPPF}

In order to enhance the unified fuel cell motor derive system performance a green plug capacitor filter GPPF comprising switchable capacitor is introduced at the DC bus. The GPPF is also controlled to absorb ripple and reduce DC side current oscillations. The idea behind the controller is to detect major excursions in the motor measurements and feed the errors to a PWM module that in turn generates the switching pulses to the filter switches in accordance with the duty ratio and the error value [5]. The MPPF used and tested with the operation of the electric motor is shown in Figure (5).

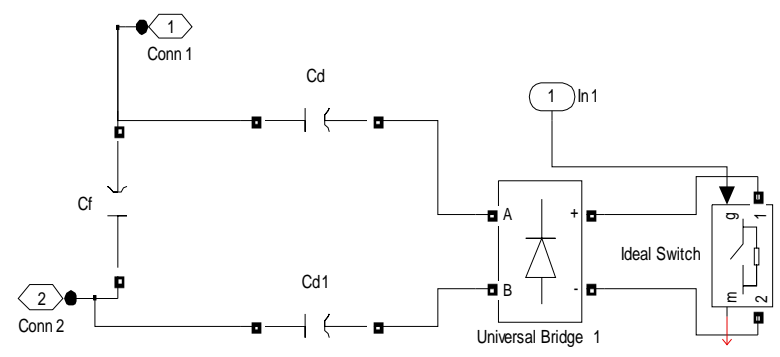

Figure (5) Green Plug Power Filter (GPPF) for stabilizing the DC bus voltage

The GPPF control scheme is based on a decoupled current and voltage components of the DC bus. The GPCF must be connected across the DC bus terminal to maintain constant $\mathrm{DC}$ voltage in order to allow operation of the VSC-converter with two control loops as shown as simulink model in Fig. 6. The primary duty of the capacitor bank is to provide a circulating current path as well as to act as voltage storage device.

As shown in Fig. 6. The input of control loop 1 is the load current which produces an error with respect to the measured value and then, the error is used for voltage regulation. The input to loop 2 is the bus voltage that has the same transfer function as the current loop.
The increased capacity of power electronic converters used in GPPF also allows for adequate sizing and optimized operation $[7,8]$. In this paper the effectiveness of the GPPF scheme is fully validated using matlab/simulink digital simulation. All of the subsystem components used in the effective FC powered pump are sub-modeled individually using the Matlab/Simulink GUI environment and combined to establish the overall system model $[9,10]$. The simulation of the proposed scheme has been carried out and the dynamic performance of the system is examined for the proposed controller.

\section{Digital Simulation Results}

The proposed fuel cell generation scheme is tested under different operation conditions. The integrated supply system model is subject to speed and load torque disturbances. This system is controlled using the described two basic dynamic independent controllers regulating the operation of the electronic interface converters, namely DC-DC chopper and the GPPF which are coordinated for common DC bus voltage control and for voltage stabilization in case of excursion of speed and torque of the pump. Firstly, the motor reached its reference speed during one second. After 6 seconds the static load of the system is increased by $50 \%$ while after 10 seconds the motor torque is increased also by $50 \%$.

Figures 7, 8, and 9 show the digital simulation dynamic responses of DC-bus voltage, motor speed, and current. From the simulation results, transient behavior can be observed, when the system is suffering from any disturbance. By employing the proposed dynamic errordriven control schemes, these transients due to the changes in motor speed, load torque are dramatically mitigated at the common DC bus. The amplitude and duration of the oscillation has been reduced using GPPF. Finally, Figure (10) displays the variation of $\mathrm{e} t 1$ including the three weighted errors in the three basic error driven loops. In addition, Figures 11, 12 and 13 display the motor speed-torque, the DC bus Voltagecurent and fuel cell voltage-current relations, respectively.

\section{Conclusions}

An efficient motorized green energy scheme using fuel cell is digitally simulated and validated using the Matlab/ Simulink/ Sim-Power Software environment. The studied scheme comprises fuel cell with all associated interface DC-DC converter, dynamic error driven controllers and a Common-DC collection Bus. The operation of the proposed energy scheme as a green generation source is fully validated under sudden load excursions including sudden changes in reference speed and motor torque of the motor. A novel GPPF green plug power filter stabilization device was validated at common DC bus 
interface for minimum voltage and current ripples. Dynamic error driven controllers were utilized to ensure stabilized constant common DC bus voltage using multiloop dynamic error-driven PI control strategies, despite fuel cell source non-linearities and load excursions.

The digital simulation results using matlab/simulink/simpower indicated that the effect of varying the motor speed and torque is compensated by controlling the DC-DC chopper duty cycle ratio. In addition the obtained digital results show the robustness of the tri-loop error driven controller for sudden load excursions. It is clearly exhibited that the proposed controller can steer the PMDC motor speed to track the time-varying reference speed more accurately than the conventional PI or PID controllers. Moreover, the motor current is smooth and free from ripple with the presented controller due to current limiting dynamic loop. The multi-loop control strategy can be further modified to ensure additional voltage stabilization and loss reduction in hybrid renewable photovoltaic-fuel cell schemes.

\section{References}

[1] B. Delfino, F. Fornari, "Modeling and control of an integrated fuel-cell wind turbine system", IEEE Power Tech. Conference Proceeding, Bologna, Vol.2, 23-26 June 20[2] J. Correa, F. Farret, L. Canha, M. Simoes, "An electrochemical-based fuel cell model suitable for electrical engineering automation approach", IEEE Transaction on Industrial Electronics, Vol. 51, issue 5, Oct. 2004.

[3] [9] L.Y. Chiu and B. M. Diong, "An improved small signal model of the dynamic behavior of PEM fuel cells," IEEE 38th IAS Annual Meeting, vol. 2, pp. 709-715, Oct. 2003.

[4] J. T. Pukrushpan, H. Peng, and A. G. Stefanopoulou,"
Simulation and analysis of transient fuel cell system performance based on a dynamic reactant flow model," Proc. of ASME IMECE'02, 2002.

[5] A. Sharaf, R. Chhetri, "A novel dynamic capacitor compensator/green plug scheme for 3-phase 4-wire utilization loads", Proceeding IEEE-CCECE conference, Ottawa, Ontario, Canada 2006.

[6] H. Fargali, F. Fahmy, M. A. El-Sayed, "Control and optimal sizing of PV-Wind powered rural zone in Egypt" Al-Azhar Engineering 10 th International conference, Cairo, Dec. 24-26, 2008.

[7] S. Yerramalla, A. Davari, A. Feliachi, "Dynamic modeling and analysis of polymer electrolyte fuel cell," IEEE Power Engineering Society Summer Meeting, vol. 1, pp. 82-86, July 2002.

[8] K. Sedghisigarchi, A. Feliachi, "Dynamic and transient analysis of power distribution systems with fuel Cells-part I: fuel-cell dynamic model." IEEE Transactions on Energy Conversion, 19(2), 423, 2004.

[9] VSubbiahS,.Suresh Kuma, S.Suresh Kuma, B.Ramakrishnan, S.S. Siva Raj," A novel Non-Linear, Carrier Free, Constant Frequency Integration Controlled Active Power Line Conditioner To Enhance Power Quality" Proceedings of the 2003 10th IEEE International Conference on Electronics, Circuits and Systems, 2003. ICECS 2003. Volume 2, 14-17 Dec. 2003 PP:834 - 837

[10] A.M. Sharaf and R. Chalet, “ A Low Cost On-Off Modulated Power Filter For Single Phase Motorized Loads", IEEE Canadian Conference on Electrical and Computer Engineering, 1998., Volume 2, 24-28 May 1998 Page(s):862 - 865 vol.2.

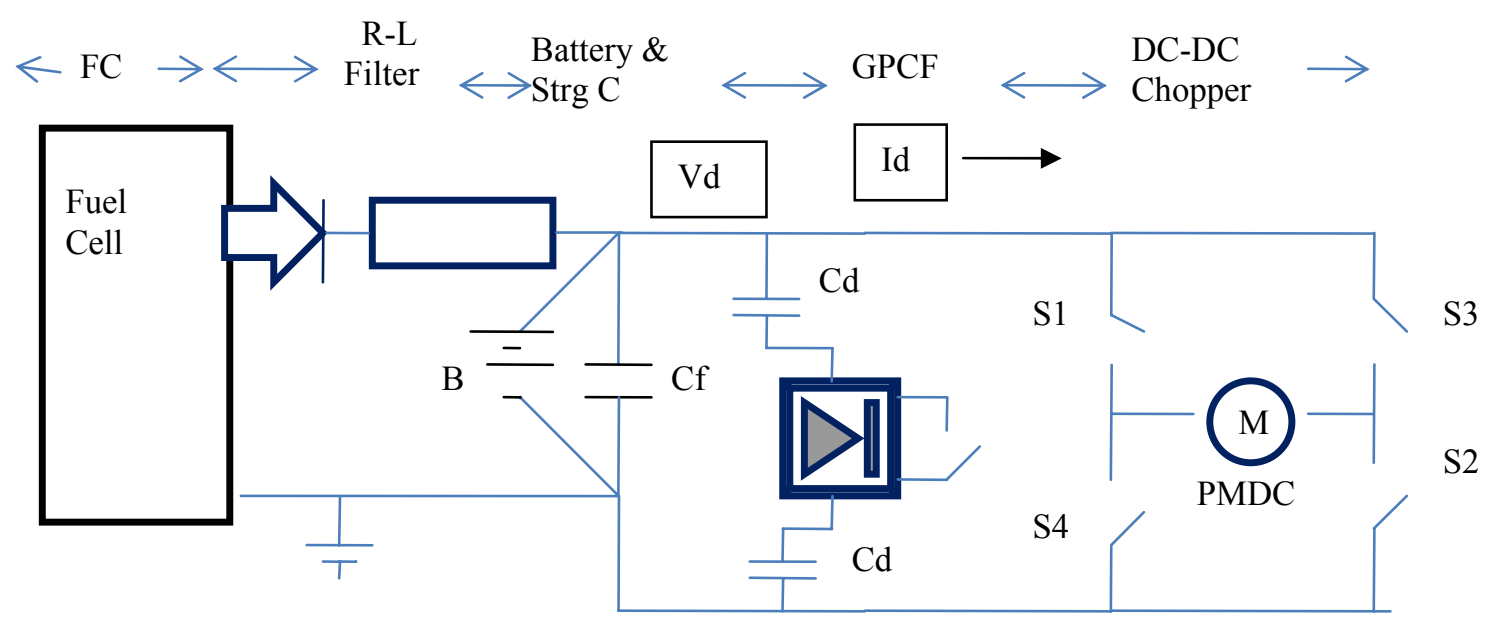

Fig.(3) Fuel Cell motorized Drive study System 


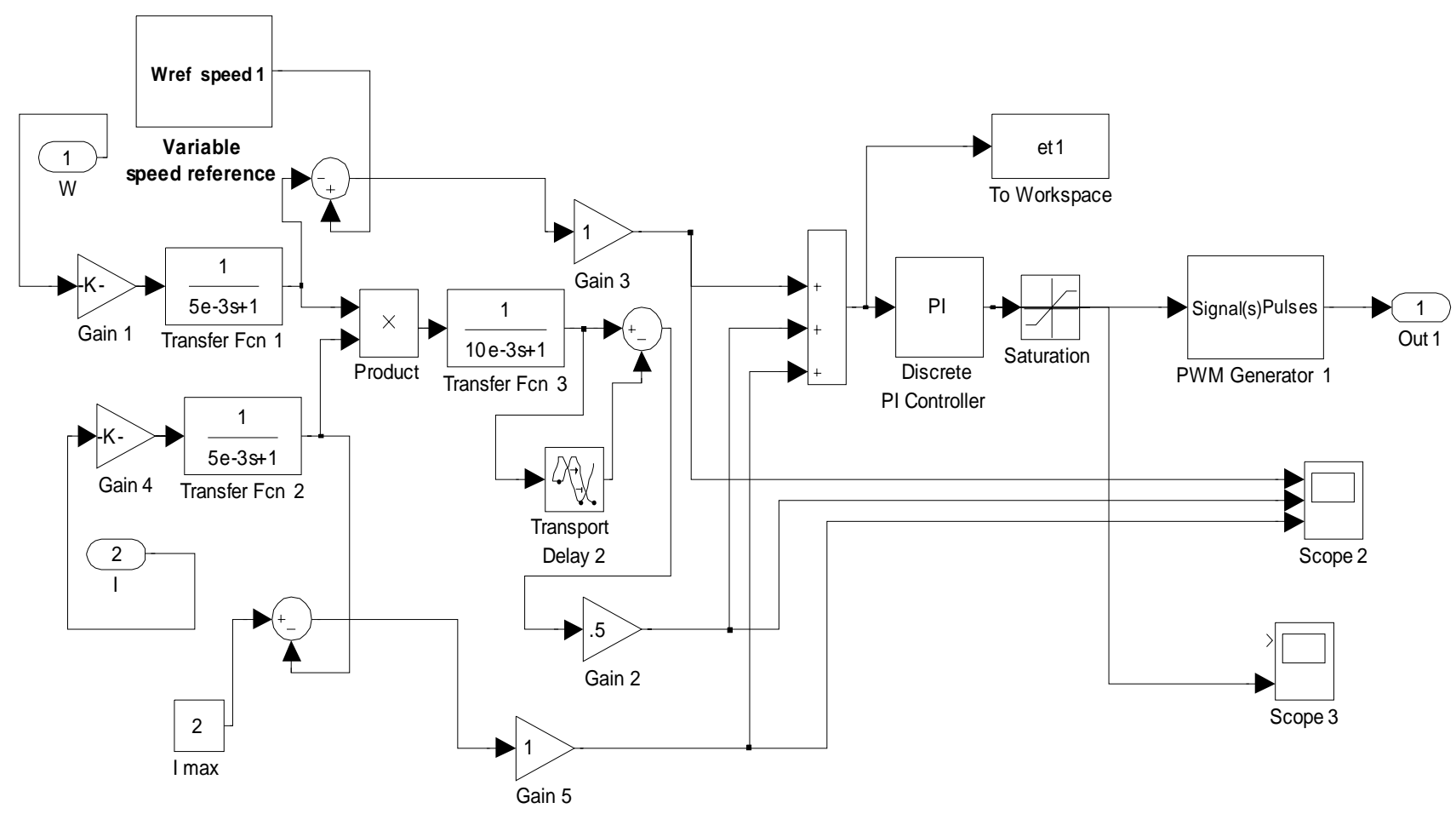

Fig.(4) Tri-Loop Dynamic Error Driven Controller of Chopper switches using Simulik modeling

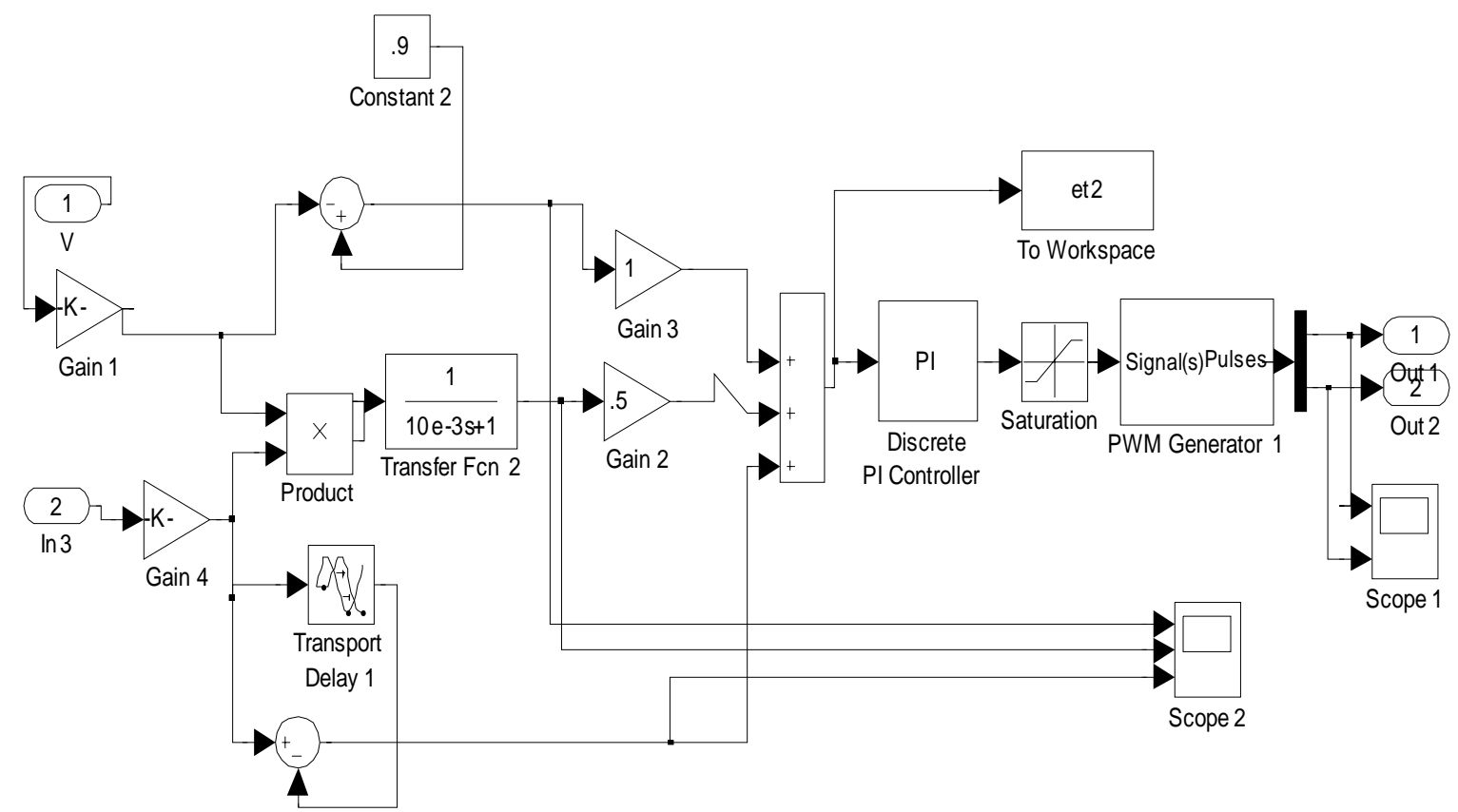

Fig.(6) Dual Loop Controller for minimum ripple common DC bus. 


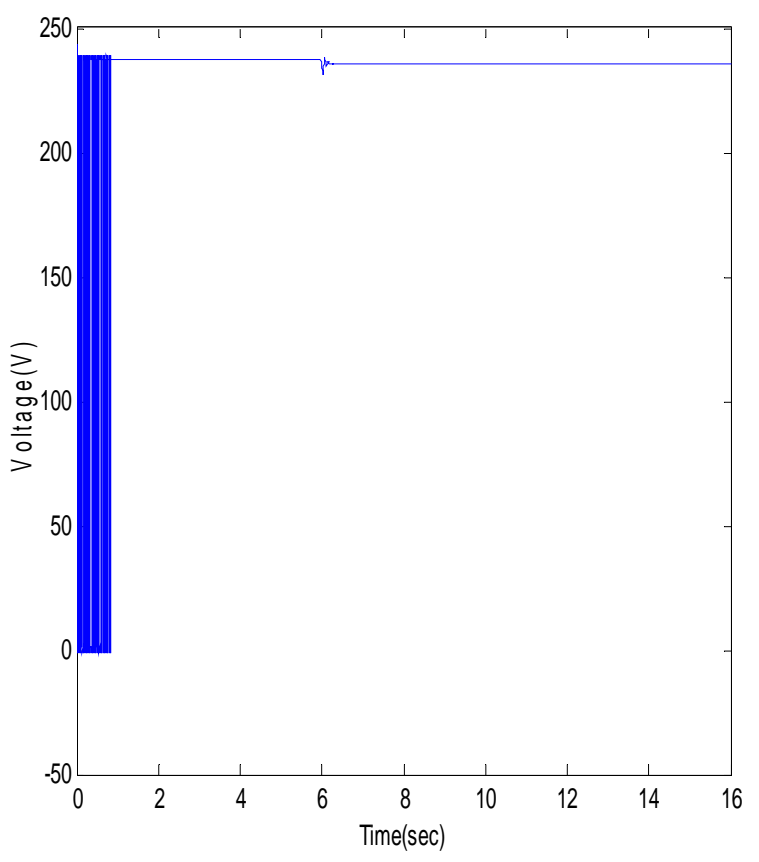

Figure (7) DC-Bus voltage variation with time under variable loading of PMDC motor

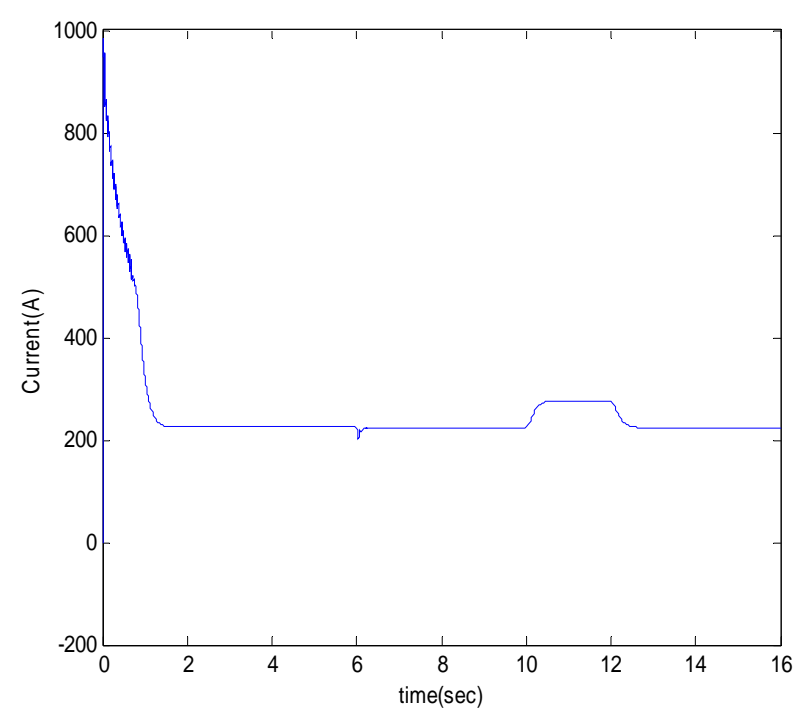

Figure(9) PMDC motor current variation with time

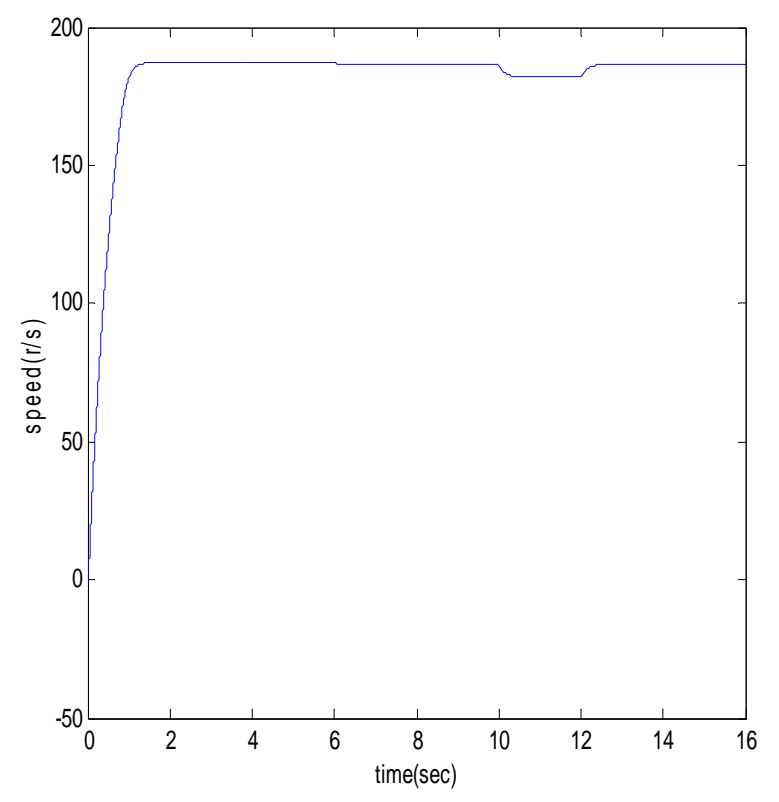

Figure (8) PMDC motor speed variation with time

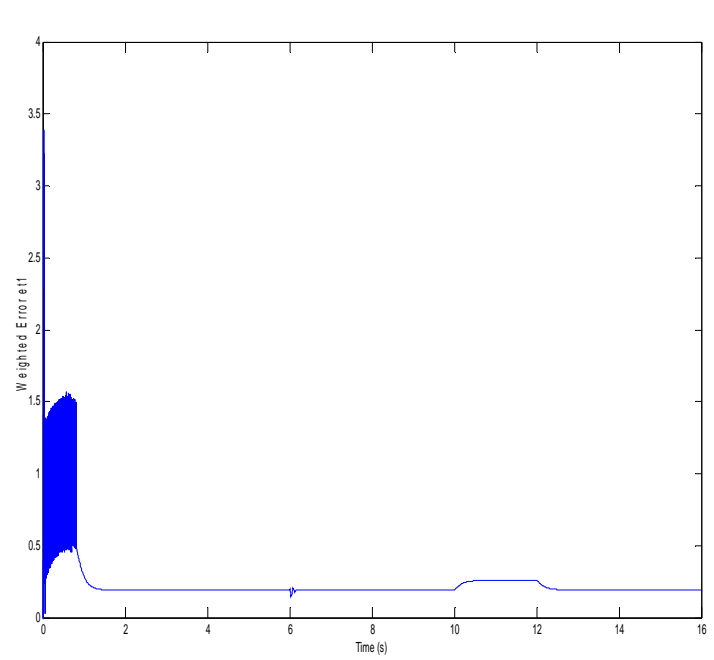

Figure (10) Variation of multi loop driven error $e_{t 1}$ with time 

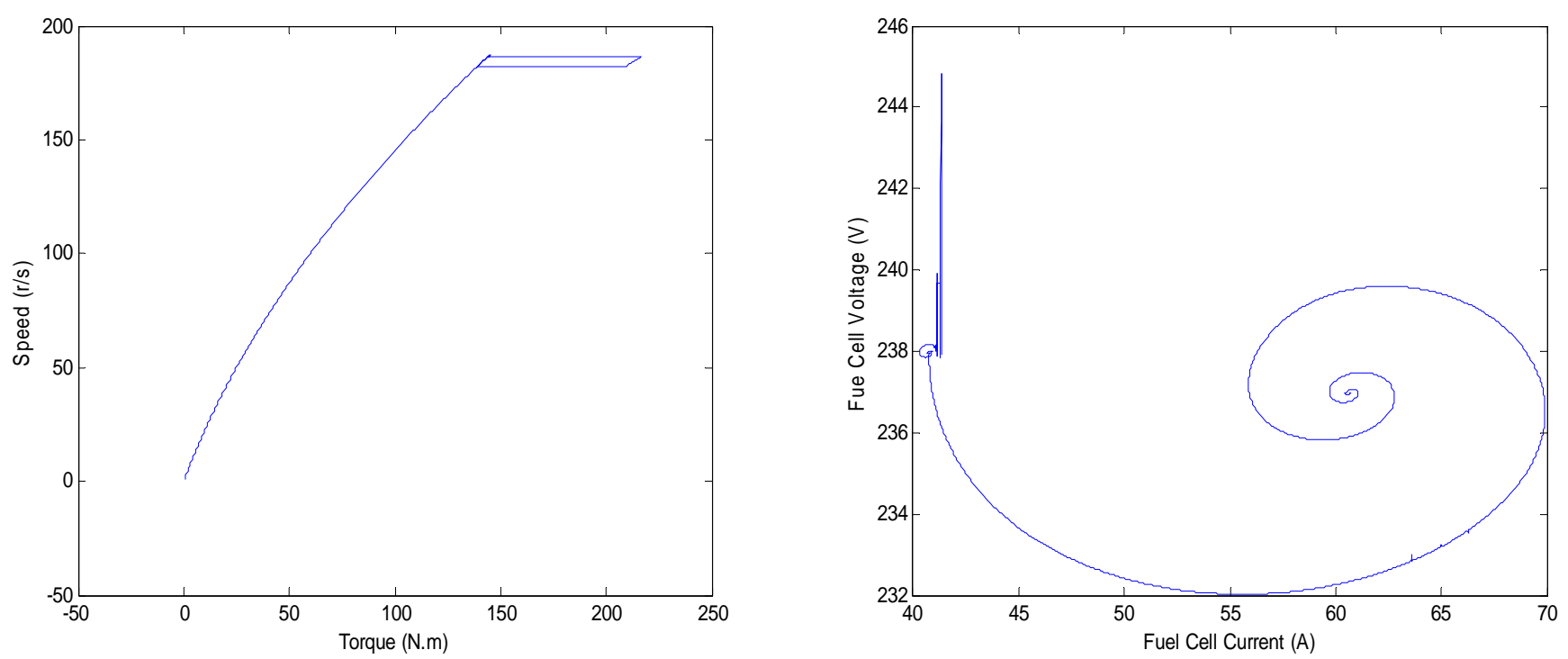

Figure (13) Voltage-current relation of the fuel cell

Figure (11) Speed-torque relation of the PMDC motor

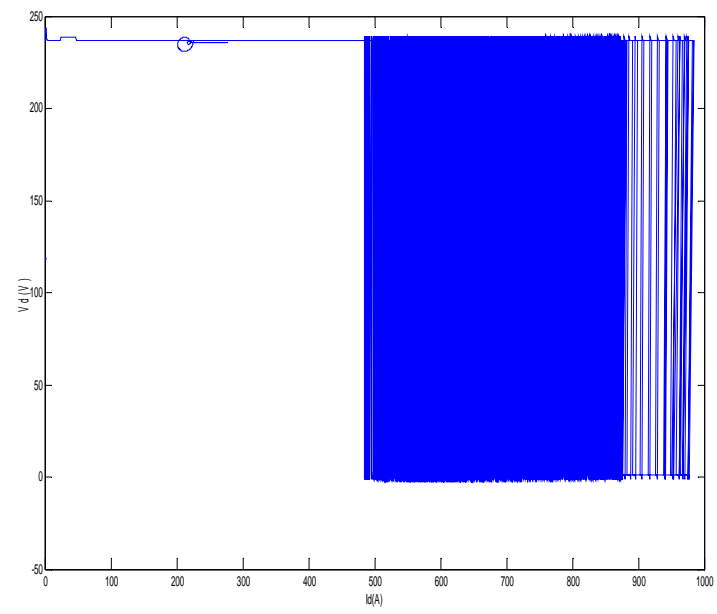

Figure (12) Voltage-current relation at the common DCbus 